\title{
Review \\ A Survey of the Literature on Order-Picking Systems by Combining Planning Problems
}

\author{
Amir Reza Ahmadi Keshavarz, Davood Jaafari *(D), Mehran Khalaj and Parshang Dokouhaki \\ Department of Industrial Engineering, Parand Branch, Islamic Azad University, Parand 3761396361, Iran; \\ ahmadikeshavarz1976@gmail.com (A.R.A.K.); mkhalaj@rkiau.ac.ir (M.K.); pdokouhaki@yahoo.com (P.D.) \\ * Correspondence: djaafari1350@gmail.com
}

Featured Application: In this paper, we review the combination of cost, equipment, warehousing, allocation, routing, batching, sequencing, and tardiness problems, and examine the scientific literature that combines order picking planning problems.

Citation: Ahmadi Keshavarz, A.R.; Jaafari, D.; Khalaj, M.; Dokouhaki, P. A Survey of the Literature on Order-Picking Systems by Combining Planning Problems. Appl. Sci. 2021, 11, 10641. https://doi.org/10.3390/ app112210641

Academic Editor: Amjad

Anvari-Moghaddam

Received: 4 October 2021

Accepted: 5 November 2021

Published: 11 November 2021

Publisher's Note: MDPI stays neutral with regard to jurisdictional claims in published maps and institutional affiliations.

Copyright: (c) 2021 by the authors. Licensee MDPI, Basel, Switzerland. This article is an open access article distributed under the terms and conditions of the Creative Commons Attribution (CC BY) license (https:/ / creativecommons.org/licenses/by/ $4.0 /)$.

\begin{abstract}
Companies have been trying continuously to reduce their logistics costs in the current competitive markets. Warehouses are important components of the logistics systems and they must be managed effectively and efficiently to reduce the production cost as well as maintain customer satisfaction. Order-picking is the core of warehouse operations and an order-picking system (OPS) is essential to meet customer needs and orders. Failure to perform the OPS process properly results in high costs and customer dissatisfaction. This research aims to investigate the state of the art in the adoption of OPS and provide a broad systemic analysis on main operating strategies such as simultaneous consideration of order assignment, batching, sequencing, tardiness, and routing need. This study reviews 92 articles, classifies combinations of tactical and operational OPS problems, and provides guidelines on how warehouse managers can benefit from combining planning problems, in order to design efficient OPS and improve customer service. Combining multiple order-picking planning problems results in substantial efficiency benefits, which are required to face new market developments.
\end{abstract}

Keywords: tardiness; order-picking system; routing; warehouse; assignment

\section{Introduction}

Manufacturing companies confront different challenges to fulfill customer orders and distinguish between them. Many manufacturing companies consider reducing and eliminating costs and improving productivity in their logistic system important improvement activities. On the other hand, the warehouse is one of the most critical in-house logistics components, playing a crucial role, among other activities, in the supply chain of any manufacturing company. To meet customer needs, the OPS, as part of the warehouse preparation process, has an important place in studies. Sixty percent of all productive activities and 55\% of warehouse operating costs include order-picking processes [1]. In each supply system, there are parts-warehousing-related activities, such as receiving parts, warehousing, ordering, and shipping along product lines [2]. For reducing warehouse operating costs, in assembly lines, it is highly significant for the company to supply necessary materials within the factory to promote its competitive power. In a factory, materials should be provided with high efficiency and flexibility. The complexity of the material and parts transportation system will lead to an increase in production simultaneously. Researchers, in recent years, have been increasingly motivated to develop OPS enhancement policies [3]. Internal logistics aspects also need a great deal of attention due to the constraints and resources available to reduce costs and increase the flexibility of production schedule changes to meet customer demands by expanding the ability of line feeding 
systems and offshore components. In this regard, using new methods of feeding materials and parts such as picking seem necessary [4]. Picking refers to some factors, including moving, picking, deploying, and packing parts according to the amount of order required to meet the production schedule [5]. Receiving materials and parts from the warehouse, preparing them, and moving them along product lines are the most strenuous activities in an internal logistic system. According to studies by Zulj et al. [5], order picking activities account for $65 \%$ of total operating costs in the internal logistics process. The order-pickings are based on the workforce and the flexibility of the workforce against changes due to existing constraints [6]. Other concepts used in the picking process are as follows: travel distance, travel time, layout, channel configuration, dimension and size of the picking, order batching, ordering of picking parts, minimizing travel distance, maximizing occupational health, picking list (required orders), stress, and psychological conditions [7]. The process of OPS is performed in different ways, as discussed below:

1. To allocate the piece to the picker

2. Picker assignment for parts

In the part assignment method for picking parts, the picker is carried, by a parts transporter or courier container, or he picks up the pieces himself [8]. In this method, the picking station is defined separately for each individual. The type of transfer operation is also proportional to the kind of concerned picking process. The part assignment method is also ergonomically beneficial to the operator [4]. On the other hand, the method of assigning a piece refers to time, when each part has its picker in a specific place [8]. Figure 1 shows the process map of the picking operation. As seen, picking begins with receiving parts from the warehouse. There are two different ways of warehousing: batching and picking operations. If the received items do not meet the quality standards and documentation required for the factory, they will be returned to the manufacturer's dock. Picking operations are performed either manually or automatically, using semi-robotic or robotic equipment. Each moving part to the picking area is also selected based on batching order and picking operations. New market developments encompassing e-commerce, globalization, increasing customer expectations, and new regulations have intensified the competition between warehouses. It has forced warehouses to manage large numbers of small orders in limited opportunities [9]. A successful e-commerce ordering process contains multiple different suppliers and programs that need to be quickly implemented.

In this regard, completing orders is one of the most important fundamentals to succeed in the on-line business. Moreover, to overcome shortcomings in the ordering process, several aspects should be carefully considered. The easier the process for the end customers is, the more satisfied they would be with you. Furthermore, to decrease the warehouse costs and applying new methods in the internal procurement system, some recent trends need to be more efficiently performed in the procurement industry. Previous studies have focused on order-picking and route selection, and warehousing operations. However, the problems of picking operations are integrated. Marchet et al. [9] provided a comprehensive empirical analysis of the choice of order-picking systems (e.g., focus and strategic decision making).

Van Gils et al. [2] focused on a combination of tactical and operational planning problems as well as the way they could support new market developments. In this regard, some issues, such as ergonomics and order tardiness, have been rarely considered by the researchers. On this account, this paper investigated how warehouse managers can take advantage of combining several operational planning issues by reviewing previous articles. This paper sought to answer the following questions through reviewing the scientific literature related to combining order-picking problems, such as cost, equipment, warehousing, assignment, routing, batching, sequencing, and tardiness:

1. Which components of OPS examined in the previous literature were effective in reducing costs?

2. What is the combination of order picking problems in the past literature that leads to cost reduction? 
3. What kind of warehouses were examined to evaluate the impact of the OPS system on cost reduction?

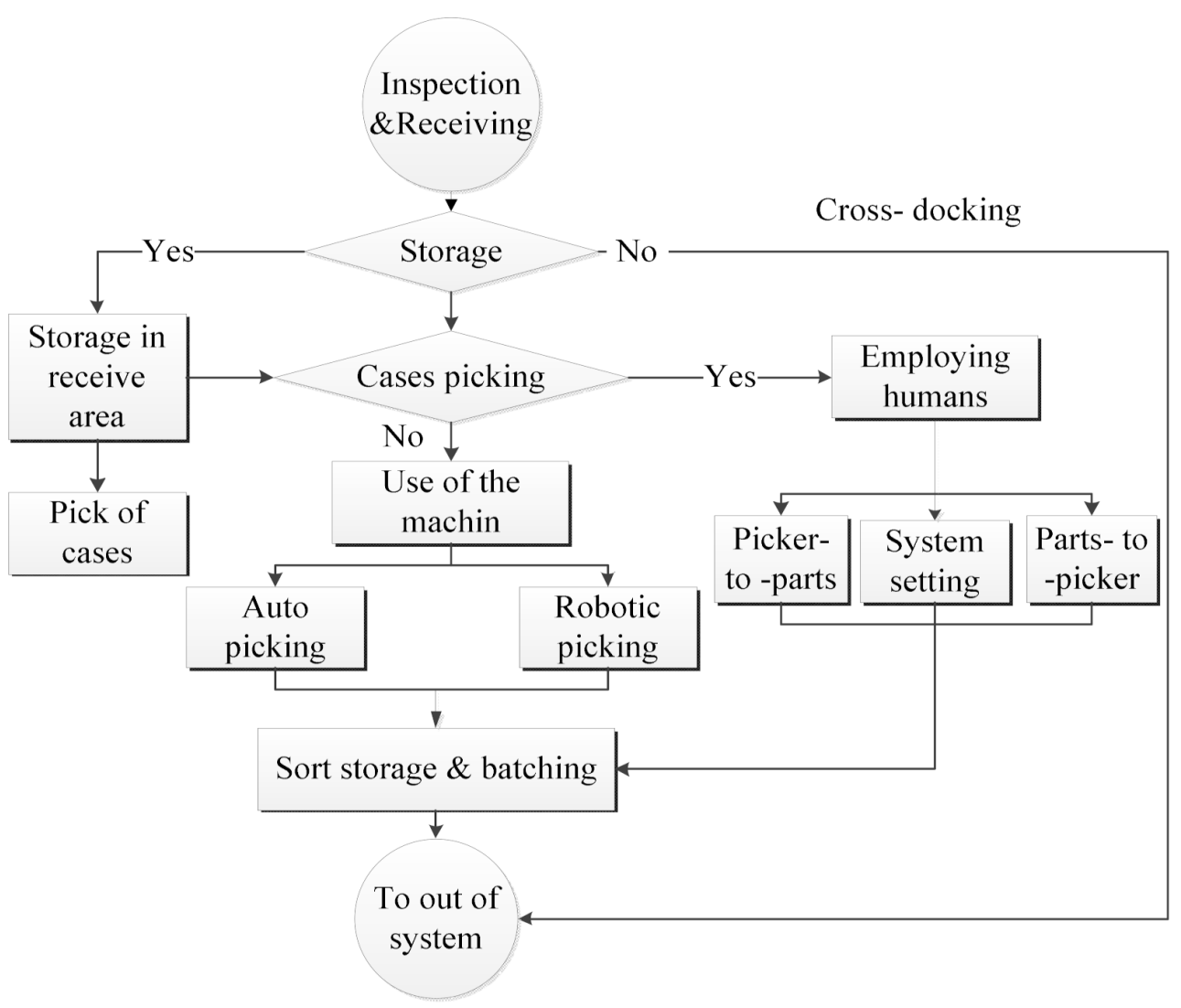

Figure 1. Process map of the picking operation [10].

Therefore, the present study aimed to investigate the problems affecting OPS and combining planning problems and how these problems have been dealt with in the previous studies. We also intended to review the solution methods used in past literature to assist researchers in future decisions to solve problems. By examining the components of the order-picking process in different warehouses, this study also sought to assist future research to identify lesser-seen problems to reduce warehouse operating costs. The remainder of this paper is organized as follows: Section 2 describes OPS literature taxonomy. Section 3 discusses the research background. Section 4 describes the literature review methodology. Section 5 discusses OPS problem planning. The managerial implications resulting from the literature overview are discussed in Section 6. Finally, Section 7 presents the conclusions.

\section{Order-Picking System Literature Taxonomy}

According to the objective of this paper, the OPS literature taxonomy surveys the scientific literature related to combining order-picking problems to answer the research questions.

This paper is organized as follows to answer the research questions; first, it considers the OPS definitions. The concepts and definitions of OPS are described in Table 1. Next, some previously conducted studies in OPS are discussed to provide a clear picture of prior research in this field. Figure 2 illustrates the classification proposed by the OPS literature. 
Table 1. The concepts and definitions.

\begin{tabular}{|c|c|}
\hline Order-Picking & $\begin{array}{l}\text { Order picking refers to the operation of retrieving items from storage } \\
\text { locations to fulfill customer orders [11]. }\end{array}$ \\
\hline Makespan & Makespan is the time when all batches are picked [12]. \\
\hline Tardiness & $\begin{array}{l}\text { Tardiness defines as the positive value between the completion time of a } \\
\text { customer order with its due date [13]. }\end{array}$ \\
\hline Routing & $\begin{array}{l}\text { Routing policies define the sequence of storage locations that should be } \\
\text { visited in each pick round to retrieve all items on a pick list [2]. }\end{array}$ \\
\hline Assignment & $\begin{array}{c}\text { Orders should be retrieved by order pickers within tight time windows. } \\
\text { The job assignment planning problem determines the sequence according } \\
\text { to which orders or batches of orders should be retrieved, as well as the } \\
\text { assignment of these (batches of) orders to a limited number of order } \\
\text { pickers [14]. }\end{array}$ \\
\hline $\begin{array}{l}\text { Order } \\
\text { Batching }\end{array}$ & $\begin{array}{l}\text { Order batching policies define rules on which customer orders to combine } \\
\text { in a single pick round. These policies can be either static (i.e., all orders are } \\
\text { known at the beginning of the planning period) or dynamic (i.e., customer } \\
\text { orders become available over time) [2]. Order batching is the grouping of } \\
\text { customer orders into picking orders (batches) [14]. }\end{array}$ \\
\hline
\end{tabular}

1. Which components of OPS examined in the previous literature were effective in reducing costs?

2. What is the combination of order picking problems in the past literature that leads to cost reduction?

3. What kind of warehouses were examined to evaluate the impact of the OPS system on cost reduction?

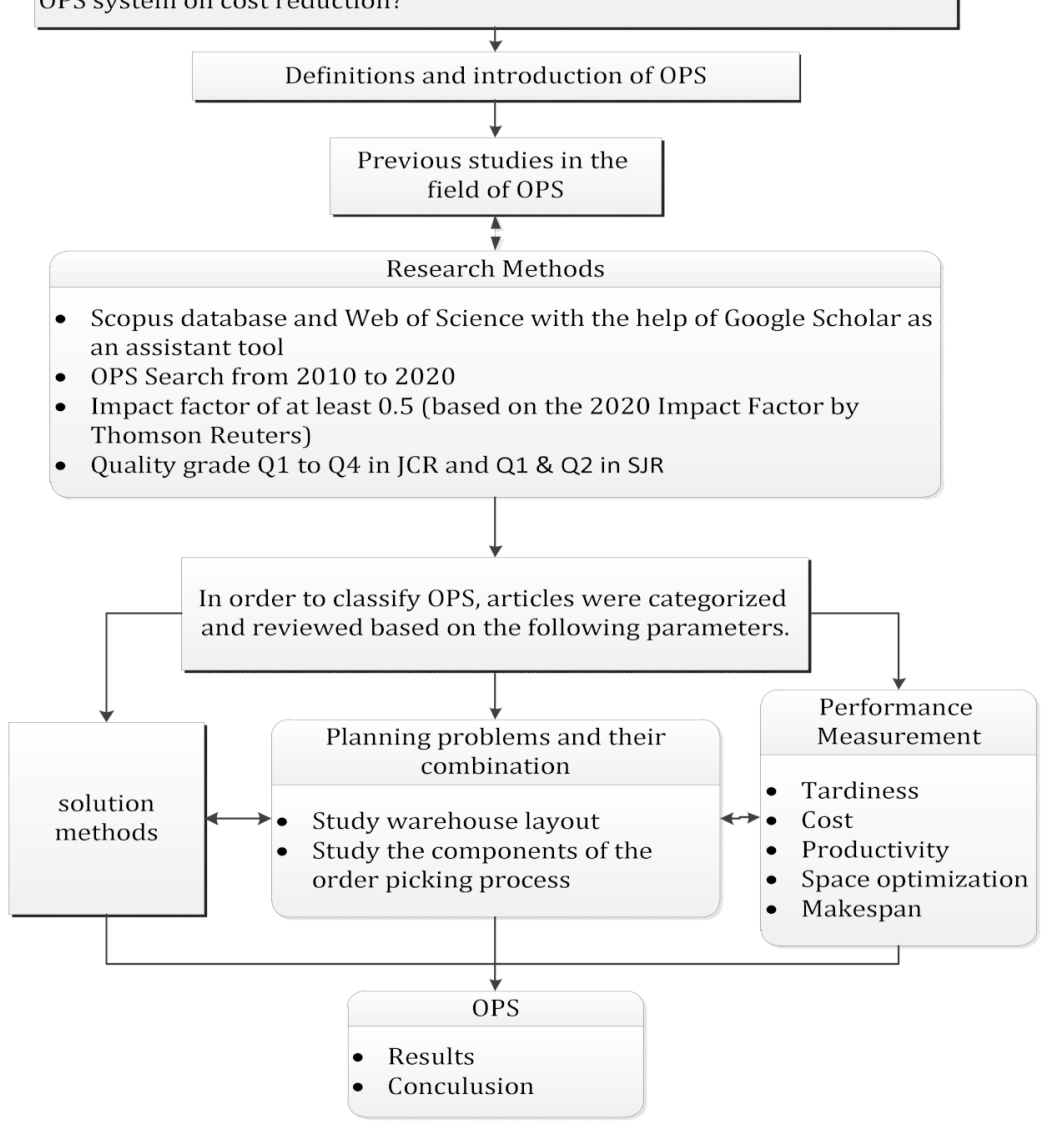

Figure 2. Proposed classification to review the OPS literature. 


\section{Order-Picking System Research Background}

During the past decades, awareness about OPS problems has been increasing worldwide thanks to industry and research. However, despite many efforts over the past few decades, OPS has not yet effectively matured. Therefore, it is essential to pay attention to warehousing activities, such as parts receiving, warehousing, orders, and internal routing [2].

It is also crucial to consider the OPS classification developed by researchers to understand previously conducted research on OPS and the boundaries of OPS research. For instance, Park and Kim [15] proposed the problems related to school bus routing. In this matter, some limitations, such as the maximum capacity of the bus, the maximum time to get on and off a bus, and the time window, were discussed. This class of surveyed problems has several subsets, including device transportation selection, routing, transport schedules, and completion time of the operation. Meanwhile, Van Gils et al. [2] developed a classification for warehouse managers' benefit. They stated that since warehouses offer several services to customers, the poor performance of warehouses may result in high costs and customer dissatisfaction with demand. Van Gils et al. [2] also declared that new market developments force warehouses to handle many orders within tight time windows. Accordingly, they studied the related review and classification of the scientific literature with combinations of tactical and operational order-picking planning problems.

Investigating a bunch of articles has also shown that the new policies on warehousing, ordering, routing, batching using fuzzy parameters, and innovative algorithms have been developed for planning resources and optimizing performance by considering the number of workers [16-19]. On the other hand, most of the studies on OPS design with a combined program have been conducted to re-evaluate warehouse activities, routing problems, equipment, order selection in a warehouse, and warehouse design [2,15]. Furthermore, some studies have been performed on the components of the order-picking process [20-22]. Some studies in recent years have sought to reduce travel time and makespan by integrating decisions on classification and scheduling of bodies [23]. Cano et al. [24,25] also investigated routing, batching, and sequencing to reduce travel time in the warehouse. Van Gils et al. [2] proposed, on a large scale, tactical and strategic decision-making issues. The advantage of the present study over the one conducted by Van Gils et al. [2] is addressing the issues of order tardiness and warehouses. Likewise, the research method used in their paper was mathematical programming, analytical models, and simulations that are different from the classification of our paper. In the current work, we tried to consider the necessity of internal aspects of procurement, the limitations, and available resources to reduce costs and increase adaptability to customer requirements by increasing the productivity, and the use of OPS systems. Although, in the review studies, the mentioned factors in the OPS system have been classified in terms of tactic, strategy, and design, they have failed to present a proper classification, including performance measurement indicators, problem-solving methods, planning, and combination. Thus, this paper reviewed a combination of cost, equipment, warehousing, assignment, routing, batching, sequencing, and tardiness in the scientific literature on a combination of planning problems. To achieve the aim of this research, which is the classification of the order-picking process, first, planning problems and their combination should be surveyed. After that, the performance measurement indicators and the chosen solution methods should be specified and investigated. The relationships between planning problems should be finally analyzed based on such indicators and solutions.

\section{Methodology of Reviewing OPS Literature}

A three-stage strategy was selected in order to identify the most relevant research papers, namely database selection, searching, and refining the sample. In this section, several valid databases were used to track the studies, and to consider an indicator for the quality of the studies, the impact factor of the articles was used and the most appropriate articles were selected thematically. 


\subsection{Database Selection}

To track academic publications, several database engines can be utilized such as Scopus, Web of Science, PubMed, and Google Scholar. Research conducted by Falagas et al. [26] showed that the Scopus database is superior to other databases. However, in another study by Wang and Waltman [27], the journal classification of Web of Science was preferred. This paper similarly employed Scopus and Web of Science databases, and Google Scholar was also used as an assistant tool.

\subsection{Sample Search}

Target articles of the present research were limited to those papers on planning and selection problems. Interestingly, this paper can also show the potential relationship between two or more planning problems. This study reviewed the recent literature in which critical issues in the picking process have been highlighted. It also focused on planning problems, such as time performance or productivity metrics that can affect economic objectives, which are very important in warehouse operations. For this purpose, "tardiness, order-picking system, routing, batching, assignment" were searched as keywords in paper titles, abstracts, and keywords among articles and review papers from 2010 to 2021 in both Scopus and Web of Science. The initial search returned 157 articles. These articles were published in English language journals with an impact factor of at least 0.5 (According to the impact factor of 2020 by Thomson Reuters) and had a quality level of Q1 to Q4 in JCR and Q1 and Q2 in SJR. Books and conference papers were excluded from the category.

\subsection{Sample Selection}

By reading the abstract of 157 papers in the first step and subsequently, by the in-depth reading of the whole paper in circumstances in which it was impossible to identify the suitability of papers, 92 articles with the most relevant content were selected. Figure 3 shows that 44 articles were published between 2010 and 2015, accounting for $48 \%$ of the total articles.

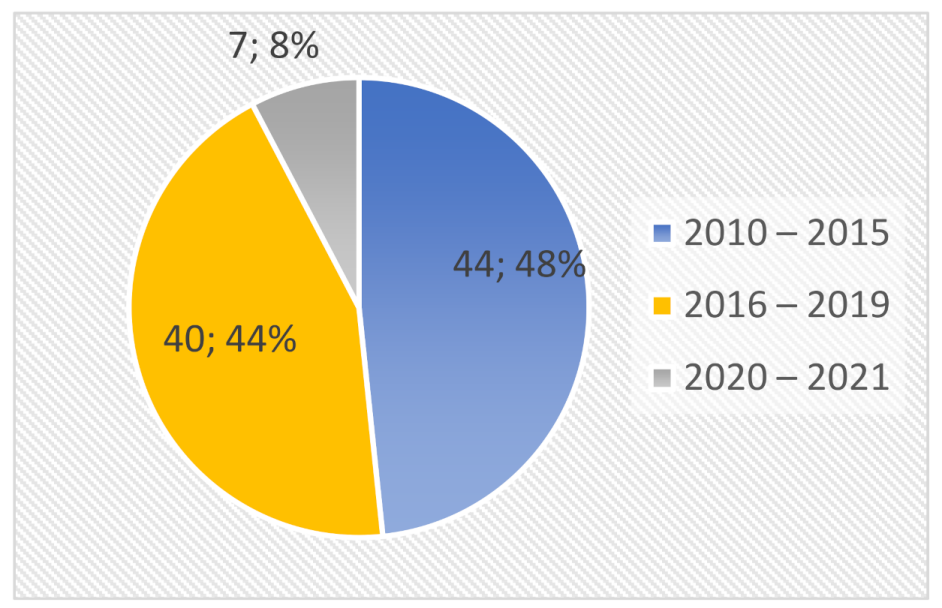

Figure 3. Article Sharing Rate based on the Number of publication Years.

To achieve the aim of the study, two issues were considered as follows: articles related to planning problems and articles exploring the interaction between planning problems in manual order selection systems. In the current research, the quality level of 85 articles in JCR and 7 articles in SJR was reviewed. Based on Figure 4, as can be seen, 61, 14, 8, and 2 of the reviewed articles were in journals of Q1, Q2, Q3, and Q4 quality in JCR, respectively. Therefore, most of the articles were selected from high-quality journals. Furthermore, the highest numbers of articles were published in the European Journal of Operational Research with 20 articles, the International Journal of Production Research with 14 articles, and the International Journal of Production Economics with 7 articles. 


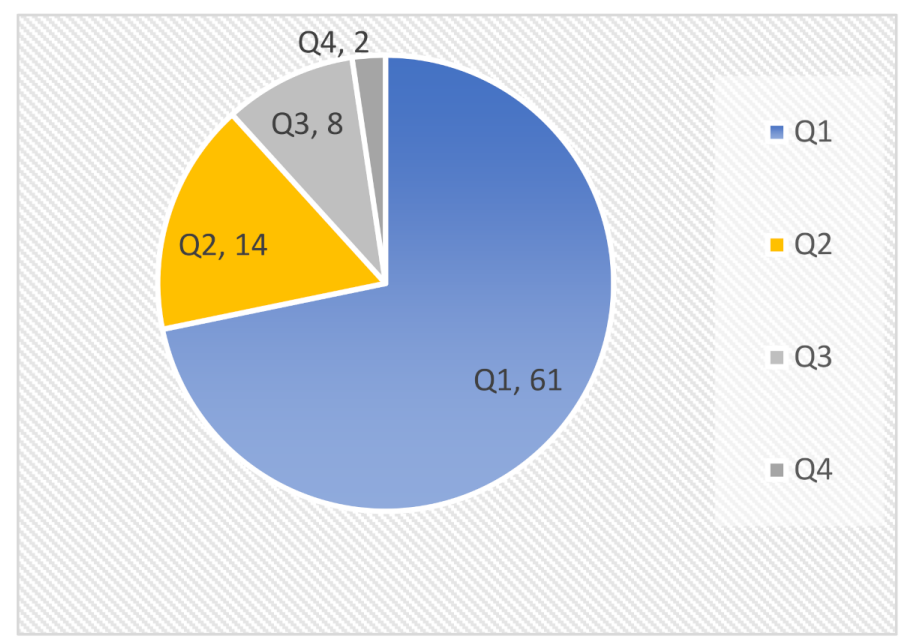

Figure 4. Number of Qualitative articles in journals.

\section{Discussion}

In this section, to help the managers decide more efficiently and overcome problems in the order-picking process, the 92 chosen articles were classified and evaluated from three perspectives. Firstly, they were surveyed considering the problems of order-picking planning issues, and the combination of problems to determine what essential issues are there in this area and which problems are simultaneously considered to optimize the order-picking performance. Such a classification helps warehouse managers determine how they can solve a combination of issues related to order-picking planning so that they consider some fundamental issues in the order-picking process. Secondly, all the articles were classified based on the performance measurements to analyse the relationship between planning problems and identify the performance indicators and their impact on the combination of problems. Thirdly, the articles were classified based on the methods used to solve the combination of order-picking planning problems to help the warehouse managers make better decisions.

\subsection{Investigating the Problems of Order-Picking Planning and Their Combination}

In this section, planning problems and their combinations were surveyed and all of the articles with at least two simultaneous planning issues were analyzed.

\subsubsection{Study the Warehouse Layout}

A warehouse comprises various areas and domains, including transportation operations, parts receiving area, parts warehousing area, and order-picking area [28]. Aisle is also referred to as the path between the rows of a cellar. Moreover, in the recent literature related to customized picking, three types of assignments have been introduced to determine the optimum anchors.

1. Assignment of storage and batching

2. Allocating storage and routing location

3. Wrapping and routing

Generally, in the design of a warehouse, all operational processes and the type of system that uses the design must be considered. Product characteristics and demand can also affect the selected system. On the other hand, in a design, compatibility between areas and requirements should be considered and the design should be so as to improve the performance of the system [29]. Figure 5 graphically depicts a typical order-picking area. 


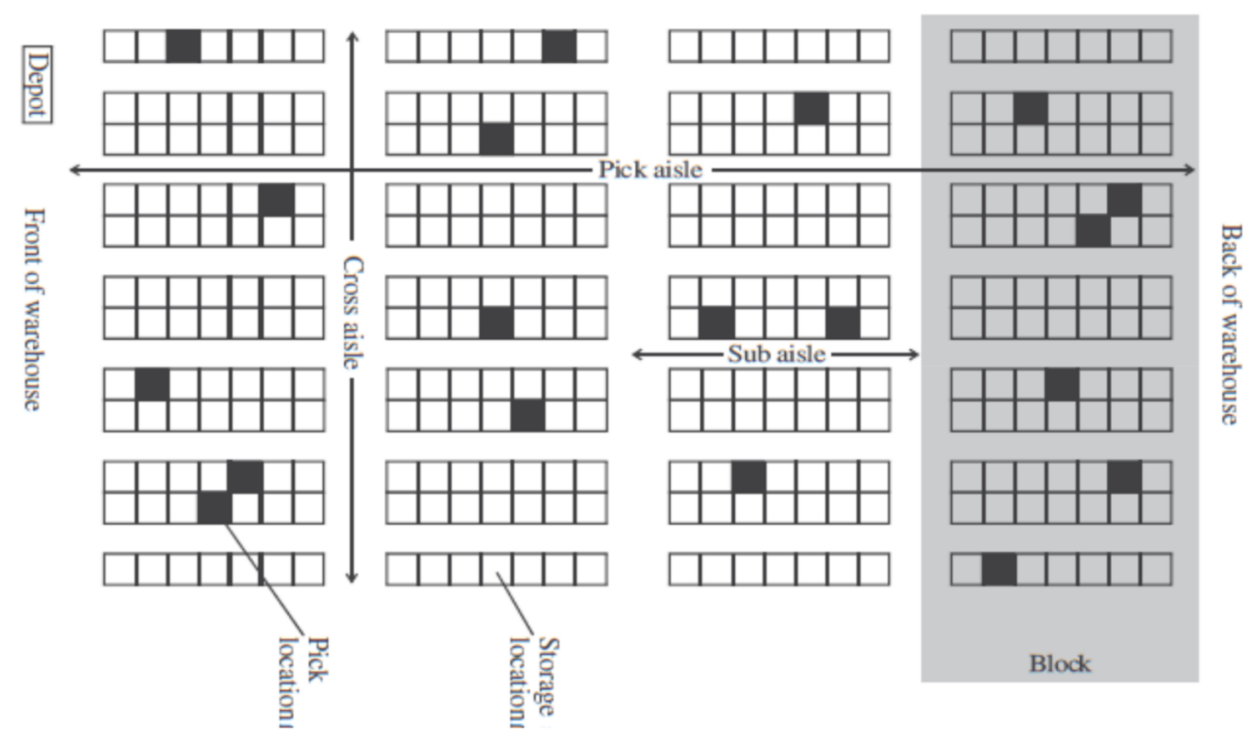

Figure 5. Order-picking Area in Stock [29].

According to Table 2, most of the studies in the warehouse were on parallel aisles and other methods were less favored by the researchers.

Table 2. Areas of study of warehouse layout types in picking.

\begin{tabular}{|c|c|c|}
\hline Auditors & Layout Method & Number \\
\hline $\begin{array}{c}\text { Ardjmand et al. [12], Azadnia et al. [13], Chen et al. [22], Cheng et al. [30] } \\
\text { Cortes et al. [31], De Vries et al. [32], Henn \& Wäscher [33], Henn [14], } \\
\text { Hong \& Kim. [34], Isler. [35], Schrotenboer et al. [36], Henn [37], } \\
\text { Men'endez et al. [38], Theys et al. [39] }\end{array}$ & Parallel aisle & 14 \\
\hline Berglund \& Batta [40], Öztürkoğlu \& Hoser [41], Öztürkoğlu et al. [42] & cross aisle & 3 \\
\hline Li et al. [43], Scholz et al. [20] & Parallel aisle with a middle aisle & 2 \\
\hline Hsieh \& Huang [44], Scholz et al. [19] & parallel aisle with cross aisle & 2 \\
\hline Matusiak et al. [45] & \multirow{2}{*}{$\begin{array}{l}\text { Parallel aisle with } 3 \text { cross aisles } \\
\text { parallel aisles and two front and } \\
\text { rear cross }\end{array}$} & 1 \\
\hline Ardjmand et al. [46] & & 1 \\
\hline Valle et al. [8], Valle \& Beasley [47] & $\begin{array}{l}\text { parallel aisles and two or more } \\
\text { cross-aisles }\end{array}$ & 2 \\
\hline Clark \& Meller [48] & Fishbone & 1 \\
\hline Kübler et al. [49], Chen et al. [50] & picker-to-parts & 2 \\
\hline Mowrey \& Parikh [51] & Mixed-width aisle & 1 \\
\hline Pan et al. [52] & pick-and-pass & 1 \\
\hline Kulak [53], Roodbergen et al. [29] & multiple cross aisles & 2 \\
\hline Cano et al. [24] & single-block and multiple-block & 1 \\
\hline \multirow[t]{2}{*}{ Henn et al. [54] } & U-shaped central aisle & 1 \\
\hline & Total & 34 \\
\hline
\end{tabular}

Van Gils et al. [2] and Scholz et al. [20] stated that the process of picking and selecting pieces for picking is complete when the picker returns to the original location after selecting the last batch. In these papers, the authors used the mathematical model to solve small samples. In contrast, for larger samples, they used a variable neighborhood descent (VND) algorithm followed by numerical experiments, showing that the algorithm offers excellent solutions for path optimization. Figure 6 introduce items, such as storage location assignment, zone assignment of the warehouse, picking area, ordering, routing, labor assignment, labor force level, and labor assignment in an interconnected structure. 


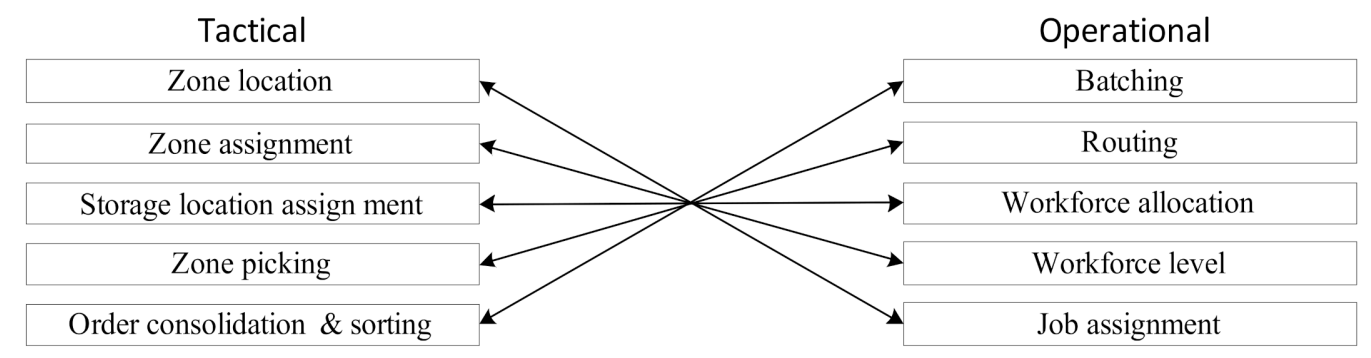

Figure 6. Order-picking process aspects (Van Gils et al. [2]).

\subsubsection{Study of the Components of the Order-Picking Process}

Investigating the assignment and sequencing of the batch to multi-pickers concurrently with the optimal routing problem, checking the overall time of the custom multi-picker picking process, or applying a categorized warehousing method are generally done to maximize profit. In Figure 7 and Table 3, components of the order-picking process can be observed. As shown, it tries to optimize order assignment (sorting and routing of the shippers resulting in minimizing process time). In addition, the workload balanced between the shippers is maintained.

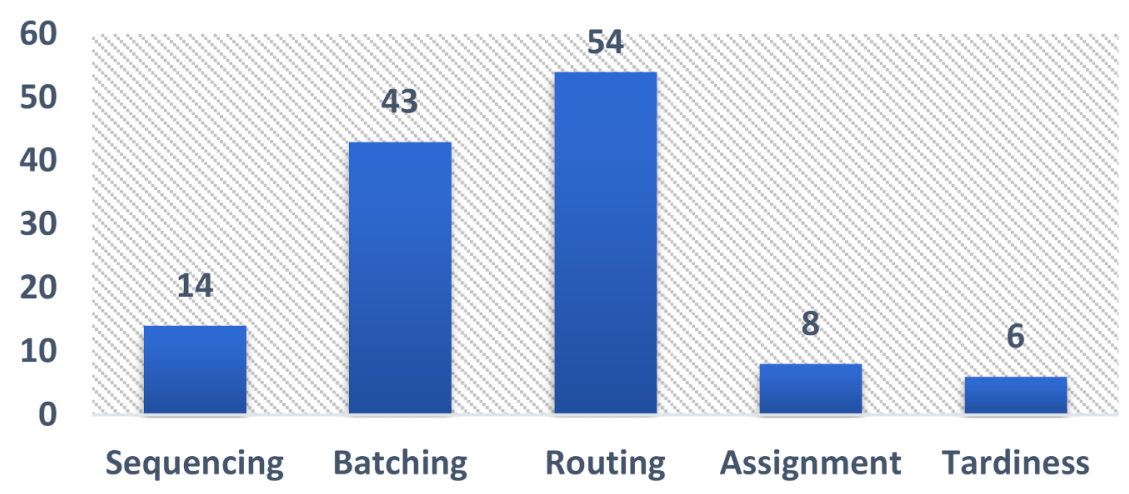

Figure 7. Frequency of study areas examined in this study.

Table 3. The Picking Process Components Study Section.

\begin{tabular}{cc}
\hline Performance Index & Articles \\
\hline Cost & 27 \\
Equipment & 9 \\
Storage space & 37 \\
Assignment & 8 \\
Routing & 54 \\
Batching & 43 \\
Sequencing & 14 \\
Tardiness & 6 \\
Ergonomy & 11 \\
\hline
\end{tabular}

There were 27 articles that considered cost (Table 3) $[6,13,15,16,18,21,30,36,41,42,50,51,55-69]$. Most of the cost-related studies focused on changes in the warehouse system, reductions in routes, improvements of the assignment process, changes in the shape and size of warehouses, travel times, and changes in warehouse design processes.

This group of studies provided methods for solving order-picking problems to help managers make better decisions. They also considered some of the most critical aspects of order-picking for identifying scheduling problems and issues with different topics. Further, some research works investigated order-picking other than resources $[13,14,20,22,33,36,70,71]$. Only the study by Scholz et al. [20] on tardiness simultaneously investigated five critical 
aspects of the order-picking process (assignment, routing, batching, sequencing, and tardiness). Four more studies $[12,60,67,72]$ also simultaneously studied routing, batching and assignment. Table 4 provides an overview of the combination of order-picking scheduling problems about various aspects of its implementation. Five main aspects defined in the order-picking process were included in 73 studies on implementing the combined planning process problem. Nineteen studies did not study these five categories and solely focused on ergonomics, cost, equipment, and storage space $[2,4,6,9,28,32,56,57,63,65,66,68,69,72-77]$. Therefore, we can state that only $20 \%$ of the reviewed studies did not focus on the five main categories of research, indicating the importance of assignment, routing, batching, sequencing, and tardiness in the order-picking process. According to Table 4, the most significant combination of routing and batching studies with 15 cases and routing with 26 cases reflects the fact that researchers have focused on routing.

Chackelson et al. [62] used both simulation solutions to simultaneously examine picking processes to reduce operating costs and a hybrid algorithm to generate batches and assignment and sequencing customer needs. Several studies studied scheduling problems together in a multi-block warehouse, while combining batching and routing into a single scheme. After assigning the order to the packer, any order picker can begin the journey to the warehouse to select and pick. The orders should be prioritized according to the production plan and delivered to the pickings. In the meantime, the lost time is one of the most important factors to consider to prevent tardiness and increase productivity. For example, when a picker stops to prepare an order batch, it is one of the cases of tardiness in the order-picking process. The studies reviewed in Van Gils et al. [2] addressed the reduction or elimination of tardiness through redesigning the picking process, batch organization, routing, prioritization, and picking activities.

In the current paper, the most studied areas were routing and storage space since a total of 21 articles studied warehousing and the design of a picking warehouse to reduce or optimize routes $[1,24,29,36,40-42,48-52,61,62,64,70-82]$.

Table 4. Areas of Study in the Picking Process.

\begin{tabular}{|c|c|c|c|c|c|c|}
\hline Auditors & Assignment & Routing & Batching & Sequencing & Tardiness & SUM \\
\hline $\begin{array}{c}\text { Cheng et al. [30], De Koster et al. [1], Ene \& Öztürk [64], } \\
\text { Franzke et al. [3], Ho \& Lin [83], Hong \& Kim [34], Hsieh \& } \\
\text { Huang [44], Kübler et al. [49], Kulak [53], Matusiak et al. [45], } \\
\text { Li et al. [43], Öztürkoğlu \& Hoser [41], Valle et al. [8], Valle \& } \\
\text { Beasley. [47], Van Gils et al. [70] }\end{array}$ & & $\sqrt{ }$ & $\sqrt{ }$ & & & 15 \\
\hline Henn [14], Men’'endez et al. [38] & & & $\sqrt{ }$ & $\sqrt{ }$ & $\sqrt{ }$ & 2 \\
\hline Scholz et al. [20] & $\sqrt{ }$ & $\sqrt{ }$ & $\sqrt{ }$ & $\sqrt{ }$ & $\sqrt{ }$ & 1 \\
\hline $\begin{array}{l}\text { Ardjmand et al. [46] } \\
\text { Acimovic \& Groves }\end{array}$ & $\sqrt{ }$ & $\sqrt{ }$ & $\sqrt{ }$ & $\sqrt{ }$ & & 1 \\
\hline $\begin{array}{c}\text { Wäscher [33], Koch \& Wäscher [85], Pan et al. [52], Schleyer \& } \\
\text { Gue [86], Tang et al. [87], Zulj et al. [5], Henn [37], Muter \& } \\
\text { Öncan [23] }\end{array}$ & & & $\sqrt{ }$ & & & 10 \\
\hline $\begin{array}{l}\text { Akilbasha \& Atarajan [56], Berglund \& Batta [40], Chabot et al. } \\
\text { [61], Chen et al. [50], Clark \& Meller [48], Cortes et al. [31], }\end{array}$ & & & & & & \\
\hline $\begin{array}{l}\text { Elbert et al. [88], Giannikas et al. [86], Glock et al. [78], Grosse } \\
\text { et al. [7], Gupta \& Kumar [17], Henn et al. [54], Isler [35], Kaur } \\
\text { \& Kumar [16], Lerher [79], Letchford et al. [89], Leung et al. [90], } \\
\text { Lu et al. [91], Mowrey \& Parikh [51], Neumann \& Medbo [80], } \\
\text { Öztürkoğlu et al. [42], Pan \& Wu [92], Park \& Kim [15], } \\
\text { Roodbergen et al. [29], Yu et al. [81], Lee \& Murray [82] }\end{array}$ & & $\sqrt{ }$ & & & & 26 \\
\hline $\begin{array}{c}\text { Cergibozan \& Tasan [59], Çeven \& Gue [60], Feng \& Hu [93], } \\
\text { Cano et al. [25] }\end{array}$ & & & $\sqrt{ }$ & $\sqrt{ }$ & & 4 \\
\hline Zhang et al. [21] & $\sqrt{ }$ & & $\sqrt{ }$ & $\sqrt{ }$ & & 1 \\
\hline $\begin{array}{c}\text { Ardjmand et al. [12], Chackelson et al. [62], Chun et al. [71], } \\
\text { Matusiak et al. [67] }\end{array}$ & $\sqrt{ }$ & $\sqrt{ }$ & $\sqrt{ }$ & & & 4 \\
\hline Schrotenboer et al. [36] & & $\sqrt{ }$ & & & $\sqrt{ }$ & 1 \\
\hline Scholz et al. [19], Theys et al. [39] & & $\sqrt{ }$ & & $\sqrt{ }$ & & 2 \\
\hline Cano et al. [24], Chen et al. [22], Scholz \& Wäscher [94] & & $\sqrt{ }$ & $\sqrt{ }$ & $\sqrt{ }$ & & 3 \\
\hline Kuo et al. [18] & $\sqrt{ }$ & & & & & 1 \\
\hline Azadnia et al. [13] & & $\sqrt{ }$ & $\sqrt{ }$ & & $\sqrt{ }$ & 1 \\
\hline Hong [95] & & & $\sqrt{ }$ & & $\sqrt{ }$ & 1 \\
\hline
\end{tabular}


Moreover, to find the most economical routes, warehouse layout, piecewise assignment, and parallel scheduling of equipment pickings, travel routes have been studied in all logistic processes and are mainly the most influential factors in terms of costing and timing.

In Scholz et al. [20], mathematical programming modeling was considered in the above categories for the first time. This research evaluated order batching and picker routing in OPS under the title of "the benefits of integrated routing." Scholz and Wäscher [92] stated that the order batching problem involves grouping a set of customized picking orders to minimize the entire picker journey so that the picking will be considered based on the calculation of the picking trip length. The strategy of this research was to simplify the order-picking activity by simplifying the custom picker journey. Cano et al. [24] introduced a mathematical programming model for the order batching and routing problem, as well as a model for the batching, sequencing, and routing issue. For this purpose, they provided some formulas for the distance traveled and the pick time in the picking process in single-block and multi-block warehouses. Moreover, Battini et al. [57] focused on human communication and ergonomic parameters in OPS by noting that most warehouse activities are manually performed by human operators. This paper also emphasized that performance and cost are profoundly dependent on availability and productivity affected by operator fatigue. A Pareto chart was also created to understand the effect of the assignment policy on the targeted activities to ultimately both provide a quantitative approach to integrate the rate of energy consumed at the estimated time for the entire OPS and introduce rest and unemployment time.

On the other side, by considering the manpower capacity and examining the operator preparation time, Battini et al. [4] stated that in addition to reducing costs, OPS also aims to improve system performance. Furthermore, various forms of assignment of the official and effective model in warehouse areas with comparative numerical capability have been developed. For example, in a study entitled "Maverick picking", Glock et al. [74] argued that having sufficient curiosity for new issues such as modifying the workflows in customized picking is a significant challenge for most warehouse managers. The purpose of the above research was to describe the Maverick picking process, its executive roots, and shape to demonstrate its potential effect on the order-picking process. This would be important since order-picking is a centralized work process and picking is a centralized and costly activity for most warehouses. It should be mentioned that $55 \%$ of the total warehouse costs related to the order-picking process. They also declared that this share would be allocated to optimal interior design, warehouse assignment methods, routing methods, order batching, and zoning [1]. Franzke et al. [3] tried to develop an integrated model to improve ergonomic and economic performance. This study developed an agent-based simulation model (ABS) for order picking in a rectangular warehouse. By employing an ABS, we can study the behavior of individual order pickers and their interactions with the environment. In the present study, we considered travel time as a distance-dependent item and stated that travel time increased by distance; thus, travel distance could be a significant goal in designing and optimizing order-picking warehouse. Battini et al. [4] showed the distribution percentage of order-picking time types as shown in Figure 8.

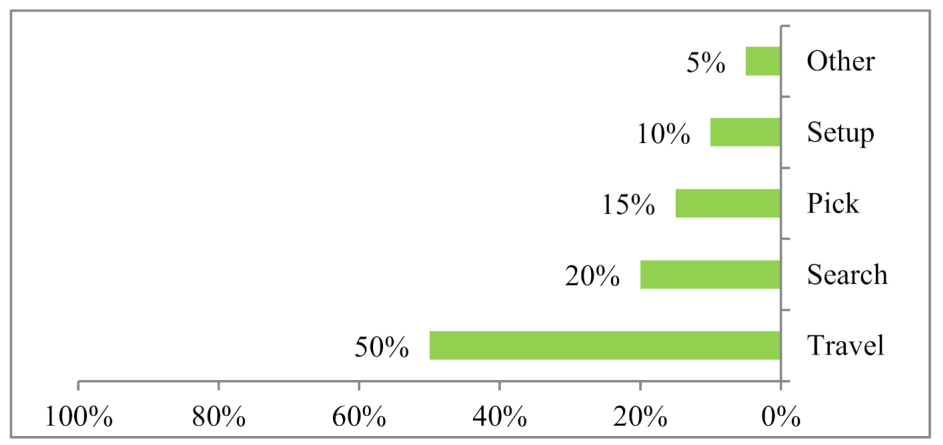

Figure 8. Distribution Percentage of Order picker Time Types [4]. 
Due to recent trends in orders, Battini et al. [4] examined the need to deliver orders in the shortest time and proposed different mathematical models to improve performance. They also examined various factors to reduce pick time. Figure 8 shows the most effective measures taken to reduce pick time by focusing on strategies related to reducing travel time, search, and pick time. Moreover, a study entitled "a discrete channel design model for an order-picking warehouse" attempted to develop a model to reduce the travel distance for picking operations, and thereby lowering the cost of operations. To this end, the concept of warehouse design with large discrete channels was introduced, where there is a linear transverse corridor called a tunnel and an efficient algorithm is used to calculate the tunnel [41]. In this article, research was conducted on how to increase the effectiveness of order-pickings using integrated warehousing, branding, regional picking, and routing policy decision-making: Delivering parts on time reduces search time and component selection. In addition, in Ene \& Öztürk [64], a study on storage location assignment and optimization of order-pickings in the automotive industry, the assignment and order of the collection system were developed by using mathematical modeling and random evolutionary optimization.

\subsection{Performance Measure}

In this section, articles were classified based on the performance measurement parameters to analyze the relationships between planning problems. Papers were also considered based on two tactical details and the details under consideration (Figure 9).

$\begin{array}{cll} & * \text { Tardiness } & * \text { Space optimization } \\ \text { Tactical } & * \text { Cost } & * \text { Makespan } \\ & * \text { Productivity } & \\ & * \text { Assignment } & * \text { Batching } \\ \text { Detail study } & * \text { Sequencing } & * \text { Routing } \\ & * \text { Tardiness } & \end{array}$

Figure 9. Study areas of the investigated articles.

\subsubsection{Tardiness}

In this section, order-picking performance was assessed using the performance index for pick and tardiness times (i.e., the difference between order completion time and order delivery time). Table 5 is an overview of tardiness minimization in the order-picking process considered in selecting the literature. Accordingly, assignment, routing, batching, and sequencing could affect tardiness minimization of the assumed goal. Table 5 also shows six research works aimed at tardiness minimization.

Table 5. Overview of the reviewed articles in minimizing Tardiness.

\begin{tabular}{ccccc}
\hline Auditors & Assignment Routing & Batching & Sequencing \\
\hline Scholz et al. [20] & $\sqrt{ }$ & $\sqrt{ }$ & $\sqrt{ }$ \\
Azadnia et al. [13] & & $\sqrt{ }$ & $\checkmark$ \\
Henn [14], Meńendez et al. [38] & & $\sqrt{ }$ & \\
Hong [95] & & $\sqrt{ }$ & \\
Schrotenboer et al. [36] & & & \\
\hline
\end{tabular}

As can be seen, few studies have examined the issue of tardiness, and only Schulz et al. [20] simultaneously examined the four issues of assignment, routing, batching and sequencing to reduce tardiness. In a parallel warehouse, Scholz et al. [20] studied a routing problem, which is a special model of the traveling salesman problem (tsp), and using mathematical model- 
ing, they showed that the problem under study is superior to the tsp formulation. Previous research has focused on only one of the problems with ops, but the study by Scholz et al. [20] is only about a specific issue on a small scale and in the form of manual picking. On the other hand, five of the six studies were related to 2015 onwards, suggesting that the issue of tardiness has been considered in recent years, although few studies have been conducted on the impact on OPS.

\subsubsection{Cost}

The process of receiving materials and parts from the warehouse and preparing is the most costly activity in the intra-factory logistics system [78]. Table 6 shows the focus of the studied articles to minimizing the cost.

Table 6. Overview of the reviewed articles in minimizing cost.

\begin{tabular}{|c|c|c|c|c|c|c|}
\hline Auditors & Assignment & Routing & Batching & Sequencing & Tardiness & Others \\
\hline $\begin{array}{l}\text { Akilbasha \& Atarajan [56], Chabot et al. [61], Chen } \\
\text { et al. [50], Kaur \& Kumar [16], Mowrey \& Parikh } \\
\text { [51], Öztürkoğlu et al. [42], Park \& Kim [15] }\end{array}$ & & $\sqrt{ }$ & & & & \\
\hline Acimovic \& Graves [55] & & & $\sqrt{ }$ & & & \\
\hline Cergibozan \& Tasan [59], Çeven \& Gue [60] & & & $\sqrt{ }$ & ป & & \\
\hline Kuo et al. [18] & $\sqrt{ }$ & & & & & \\
\hline Chackelson et al. [62], Matusiak et al. [67] & d & $\sqrt{ }$ & $\sqrt{ }$ & & & \\
\hline Zhang et al. [21] & $\sqrt{ }$ & & $\sqrt{ }$ & $\sqrt{ }$ & & \\
\hline Azadnia et al. [13] & & $\sqrt{ }$ & $\sqrt{ }$ & & $\sqrt{ }$ & \\
\hline $\begin{array}{c}\text { Cheng et al. [30], Ene \& Öztürk [64], Öztürkoğlu \& } \\
\text { Hoser [41] }\end{array}$ & & $\sqrt{ }$ & $\sqrt{ }$ & & & \\
\hline $\begin{array}{c}\text { Schrotenboer et al. [36] } \\
\text { Battini et al. [57], Bevan [58], Chien et al. [63], Grosse } \\
\text { et al. [6], Grosse et al. [65], Manzini et al. [66], } \\
\text { Schwerdfeger \& Boysenl [68], Tappia et al. [69] }\end{array}$ & & $\sqrt{ }$ & & & $\sqrt{ }$ & $\sqrt{ }$ \\
\hline
\end{tabular}

However, the reviewed studies showed that past literature has focused on cost reduction through routing and batching so that 18 out of 27 studies have used these two issues to reduce costs, and only 2 studies have examined the effect of tardiness on costs. However, the effect of different combinations of sequencing, tardiness, and assignment on cost has not been observed.

\subsubsection{Productivity}

Thirteen further studies focusing on the goal of maximization of productivity were reviewed. The reviewed articles pointed out that:

1. Small size orders are performed with a great variety of parts.

2. Some orders will affect the efficiency of the order-picking process due to either the seasonality of the order, the intention of moving the order forward, or various delivery locations based on point-of-sale information. Table 7 shows an overview of the studied articles regarding the maximum productivity of the order-picking process.

Table 7. Overview of the reviewed articles in maximization of Productivity.

\begin{tabular}{|c|c|c|c|c|c|c|}
\hline Auditors & Assignment & Routing & Batching & Sequencing & Tardiness & Others \\
\hline Li et al. [48], Van Gils et al. [70] & & $\sqrt{ }$ & $\sqrt{ }$ & & & \\
\hline Chen et al. [22] & & $\sqrt{ }$ & $\sqrt{ }$ & $\sqrt{ }$ & & \\
\hline Matusiak et al. [67] & $\sqrt{ }$ & $\sqrt{ }$ & $\sqrt{ }$ & & & \\
\hline Leung et al. [90], Neumann \& Medbo. [80] & & $\sqrt{ }$ & & & & \\
\hline Hong [95] & & & $\sqrt{ }$ & & $\sqrt{ }$ & \\
\hline Henn \& Wäscher [33], Koch \& Wäscher [85] & & & $\sqrt{ }$ & & & \\
\hline $\begin{array}{c}\text { Bevan [58], Calzavara et al. [72], De Vries et al. [32], } \\
\text { Tappia et al. [69] }\end{array}$ & & & & & & $\sqrt{ }$ \\
\hline
\end{tabular}


As can be seen in Table 7, most studies have focused on routing and batching. However, Matusiak et al. [67] simultaneously studied categories of assignment, routing, and batching to maximize the productivity in OPS. Chen et al. [22] also simultaneously evaluated the effect of routing, batching, and sequencing on efficiency. Matusiak et al. [67] tried to reduce the total processing time by focusing on the skill level of the operator and the individual difference between the pickers. They changed the batching methods and saved a total of $6 \%$ in time. They further used multi-level modeling and used the Adaptive Large Neighborhood Search algorithm to solve the model. In the warehouse, Chen et al. [22] used a routing problem with a limited domain, which is not applicable to large-scale problems. They employed an integer model focusing on sequencing, batching, and routing, and used genetic algorithms to solve the problem. The above research works are more important than other ones in Table 7, but in the reviewed body of research, the role of operator skills was less seen.

\subsubsection{Space Optimization}

Warehousing management policy is a crucial issue in logistic management. It must be managed effectively and efficiently to reduce the production cost as well as the customer satisfaction. Synchronized zoning system is a warehousing management policy that aims to increase the warehouse utilization and customer satisfaction by reducing the customer waiting time [18]. Table 8 shows the studies performed to optimize the space available for OPS.

Table 8. Overview of the reviewed articles on Space optimization.

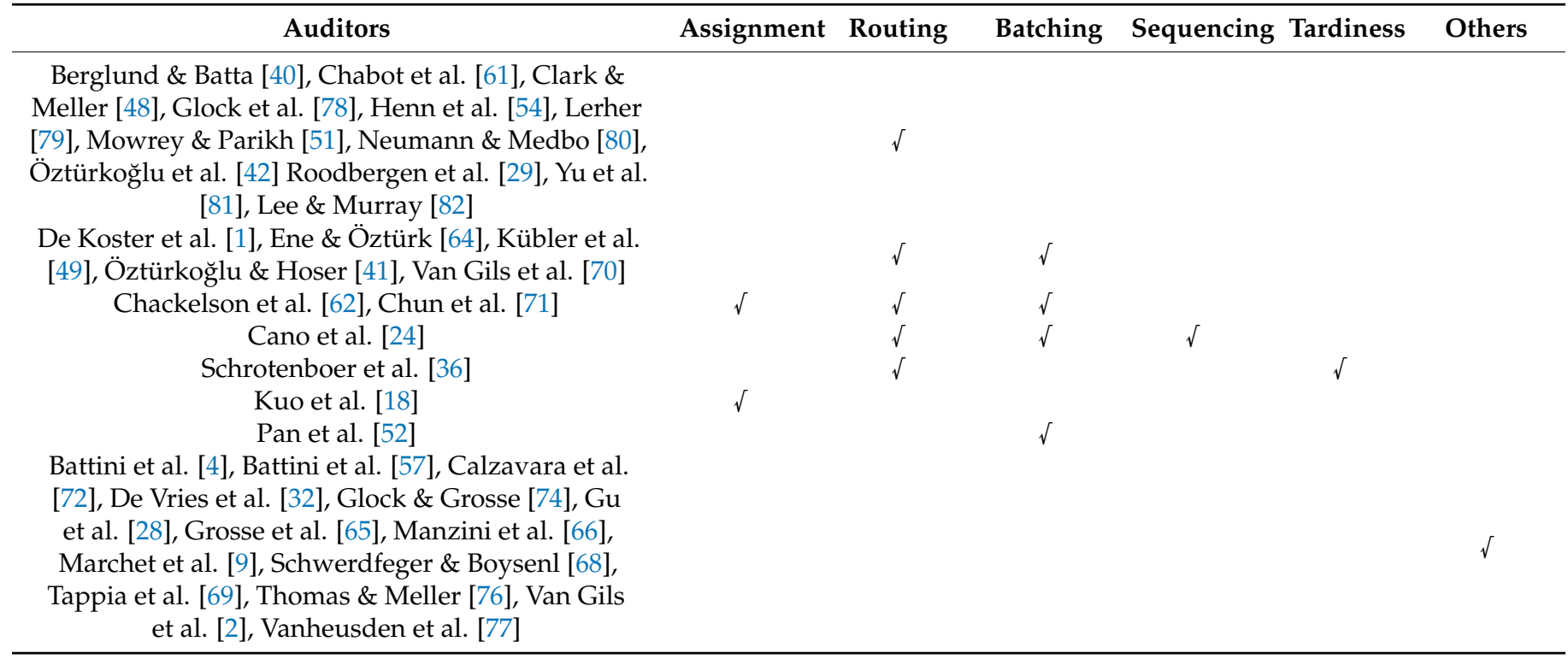

There were 37 studies in this field, with 2 articles on assignment, routing, and batching simultaneously. As can be seen in Table 8, most studies focused on routing. Chackelson et al. [62] examined an experimental method with the help of simulation for the discrete events in the warehouse design process. They examined a retail distributor as well as the impact of different parameters on process design, while Cano et al. [24] studied twodimensional and three-dimensional single-block warehouses. They applied the TSP model with several pickers and modeled the results that are used for manual systems.

\subsubsection{Makespan}

To minimize the order-picking makespan, it is necessary to simultaneously solve order batching, assignment and pickers routing. Table 9 shows six research works aimed at makespan minimization. 
Table 9. Overview of the reviewed articles on Minimization of Makespan.

\begin{tabular}{ccccc}
\hline Auditors & Assignment & Routing & Batching & Sequencing Tardiness \\
\hline Ardjmand et al. [46] & $\sqrt{ }$ & $\sqrt{ }$ & $\sqrt{ }$ & $\sqrt{ }$ \\
Ardjmand et al. [12] & $\sqrt{ }$ & $\sqrt{ }$ & $\sqrt{ }$ & \\
Zulj et al. [5], Henn [37], Muter \& Öncan [23] & & & $\sqrt{ }$ & \\
Lee \& Murray [82] & & $\sqrt{ }$ & & \\
\hline
\end{tabular}

According to Table 9, Ardjmand et al. [46] studied the simultaneous analysis of assignment, routing, batching, and sequencing. The authors studied an on-line order batching problem where orders become available over time on a dynamic basis and the total completion time of all orders in a certain time period needed to be minimized [46]. It is clear that there are a few studies that consider makespan as the objective function.

\subsection{Research and Solution Methods}

In this section, all the reviewed articles were classified according to the solving methods used in the reviewed articles. The following research methods have been proposed in the literature to analyze interactions of order-picking policies or to integrate multiple order-picking planning problems: analytical models, simulation experiments, and mathematical programming. Analytical models refer to a set of mathematical equations that approximate the performance of a system by relating the performance variable to multiple system parameters. Simulation experiments are defined as methods to imitate the system's operations or characteristics with the purpose of conducting numerical experiments to provide insights into the behavior of the system. Mathematical programming models refer to the set of mathematical expressions that describe the problem consisting of an objective function and constraints to define the overall structure of the problem. Figure 10 shows the distribution of these research methods in the scientific literature.

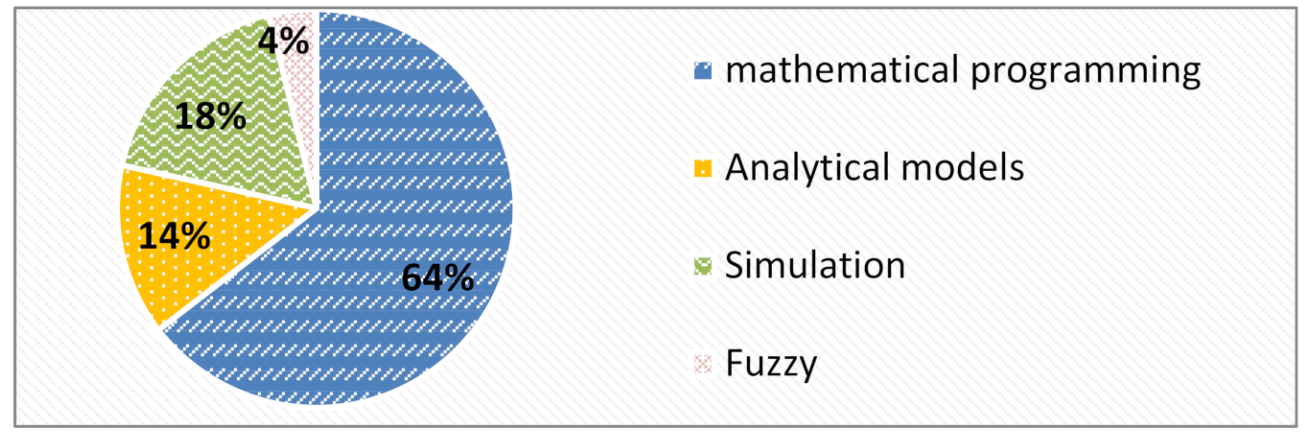

Figure 10. Solving methods used in Studies.

According to Figure 10, it can be seen that the mathematical programming method has been the most commonly used solution in the research works. The use of simulation and analytical models as a research method to integrate different order-picking planning problems are limited. Thirteen studies used the simulation method, and 11 studies used analytical models. Table 10 shows the frequency of the solution methods used in the articles.

According to Table 10, it can be seen that most of the research works (51 articles) focused on mathematical programming methods. In addition, the Variable Neighborhood Search Algorithm and Genetic Algorithm are by far the most popular method to analyze combinations of order-picking planning problems. 
Table 10. Studies using mathematical programming methods.

\begin{tabular}{|c|c|c|c|c|c|c|}
\hline Articles & Solution Methods & Assignment & Routing & Batching & Sequencing & Tardiness \\
\hline $\begin{array}{l}\text { Chen et al. [50], Chen et al. [22], Cheng et al. [30], } \\
\text { Li et al. [43] }\end{array}$ & $\mathrm{ACO}$ & $\sqrt{ }$ & $\sqrt{ }$ & $\sqrt{ }$ & $\sqrt{ }$ & \\
\hline $\begin{array}{l}\text { Koch \& Wäscher [85], Leung et al. [90], } \\
\text { Schrotenboer et al. [36], Feng \& Hu [93], Cano } \\
\text { et al. [25], Ene \& Öztürk [64], Azadnia et al. [13], } \\
\text { Chen et al. [22], Kuo et al. [18] }\end{array}$ & GA & $\sqrt{ }$ & $\sqrt{ }$ & $\sqrt{ }$ & $\sqrt{ }$ & $\sqrt{ }$ \\
\hline $\begin{array}{c}\text { Kuo et al. [18], Cheng et al. [30], Chun et al. [71], } \\
\text { Öztürkoğlu et al. [42] }\end{array}$ & PSO & $\sqrt{ }$ & $\sqrt{ }$ & $\sqrt{ }$ & & \\
\hline $\begin{array}{c}\text { Cortes et al. [31], Kulak [53], Zulj et al. [5], Henn } \\
\text { \& Wäscher [33] }\end{array}$ & TS & & $\sqrt{ }$ & $\sqrt{ }$ & & \\
\hline Ardjmand et al. [12], Ardjmand et al. [46] & PSA-ACO & $\sqrt{ }$ & $\sqrt{ }$ & $\sqrt{ }$ & $\sqrt{ }$ & \\
\hline Matusiak et al. [45] & $\mathrm{A} *$-algorithm & & $\sqrt{ }$ & $\sqrt{ }$ & & \\
\hline Matusiak et al. [45] & SA & & $\sqrt{ }$ & $\sqrt{ }$ & & \\
\hline $\begin{array}{l}\text { Ene \& Öztürk [64], Li et al. [43], } \\
\text { Manzini et al. [66] }\end{array}$ & integer programming & & $\sqrt{ }$ & $\sqrt{2}$ & & \\
\hline Scholz et al. [19] & exact method & & $\sqrt{ }$ & & $\sqrt{ }$ & \\
\hline Ardjmand et al. [46] & CG & $\sqrt{ }$ & $\sqrt{ }$ & $\sqrt{ }$ & $\sqrt{ }$ & \\
\hline $\begin{array}{l}\text { Glock \& Grosse [74], Isler [35], Kübler et al. [49], } \\
\text { Theys et al. [39], Valle \& Beasley [47], Zhang et al. } \\
\text { [21], Henn [37], Vanheusden et al. [77] }\end{array}$ & Heuristic & $\sqrt{ }$ & $\sqrt{ }$ & $\sqrt{ }$ & $\sqrt{ }$ & \\
\hline $\begin{array}{l}\text { Zulj et al. [5], Chabot et al. [61], Henn [14], } \\
\text { Matusiak et al. [67], Scholz et al. [20], } \\
\text { Men'endez et al. [38], Muter \& Öncan [23] }\end{array}$ & VNS & $\sqrt{ }$ & $\sqrt{ }$ & $\sqrt{ }$ & $\sqrt{ }$ & $\sqrt{ }$ \\
\hline Tang et al. [87] & Lagrang & & & $\sqrt{ }$ & & \\
\hline Valle et al. [8], Lee \& Murray [82] & $\mathrm{B} \& \mathrm{~B}$ & & $\sqrt{ }$ & $\sqrt{ }$ & & \\
\hline Henn \& Wäscher [33] & Hill climbing & & & $\sqrt{ }$ & & \\
\hline $\begin{array}{l}\text { Andriansyah et al. [84], Berglund \& Batta [40], } \\
\text { Chackelson et al. [62], Chien et al. [63], Elbert } \\
\text { et al. [88], Giannikas et al. [96], Ho \& Lin [83], } \\
\text { Hong \& Kim [34], } \\
\text { Hsieh \& Huang [44], Lu et al. [91], Pan et al. [52], } \\
\text { Roodbergen et al. [29], Tappia et al. [69], }\end{array}$ & Simulation & $\sqrt{ }$ & $\sqrt{ }$ & $\sqrt{ }$ & & \\
\hline Gupta \& Kumar [17], Kaur \& Kumar [16] & Fuzzy & & $\sqrt{ }$ & & & \\
\hline $\begin{array}{c}\text { Acimovic \& Graves [55], De Koster et al. [1], } \\
\text { Glock et al. [78], Grosse et al. [7], } \\
\text { Grosse et al. [6], Grosse et al. [65], } \\
\text { Henn et al. [54], Mowrey \& Parikh [51] } \\
\text { Schleyer \& Gue [86], Thomas \& Meller [76], Van } \\
\text { Gils et al. [70], }\end{array}$ & Analytical models & & $\sqrt{ }$ & $\sqrt{ }$ & & \\
\hline $\begin{array}{l}\text { Battini et al. [4], Battini et al. [57], Calzavara et al. } \\
\text { [72], Cano et al. [24], Çeven \& Gue [60], Hong } \\
\text { [95], Lerher [79], Öztürkoğlu \& Hoser [41], Pan \& } \\
\text { Wu [92], Scholz \& Wäscher [94], Schwerdfeger \& } \\
\text { Boysenl [68] }\end{array}$ & Other & & $\sqrt{ }$ & $\sqrt{ }$ & $\sqrt{ }$ & $\sqrt{ }$ \\
\hline
\end{tabular}

In this review article, papers on OPS published from 2010 to 2021 with scientific degrees shown in Figure 4 were comprehensively studied. First, the articles, according to Table 2, examined the warehouses mentioned in the papers, and then it was found that that parallel aisles, with 14 cases, were the most studied warehouses. Next, the picking order problems were investigated (Figure 7 and Table 3). Then, the combinations of orderpicking problems were surveyed (Table 4). Afterward, the objectives of the articles were addressed, and the reviewed articles were classified in terms of minimizing tardiness (Table 5). Moreover, articles on cost minimization were addressed (Table 6). Later, studies on maximum productivity and storage space improvement were addressed (Tables 7 and 8 , respectively). Finally, the objectives of articles on minimizing makespan were provided (Table 9) and the research methods used in the reviewed papers were presented in Table 10.

\section{Results}

Considering the assumptions made in the introduction and according to the information obtained from Tables 3, 4 and 6, the review process of articles from 2010 to 2021 in the present study showed the researchers' attention to reducing operating costs by focusing on order selection activities such as routing, batching, and space storage. In Figure 3, it is also 
evident that the studies conducted in the field of OPS from 2010 to 2021 have had a similar course, showing that OPS issues are still of interest to researchers. Although most studies initially focused on routing and batching problems, researchers' attention, in recent years, has been directed to simultaneously combining problems and considering issues such as latency and makespan. The results of this review study revealed the importance of integrating the problems related to multi-objective picking planning to effective management of order-picking operations. The results indicated that the time horizon of decisions could significantly affect the proper approach to solving the hybrid planning problems. On the one hand, issues can be combined by analyzing the interactions between predetermined policies specific to each planning problem. On the other hand, two or more planning problems can be integrated and solved. In this section, the results of research questions are discussed. Figure 2 and Table 4 present an overview of the approach implemented in most articles intended to solve any combination of picking planning problems, as well as the number of articles that analyze each combination. Regarding the first research question, Figure 7 and Table 3 show that in the order-picking area, a combination of planning problems, such as cost, equipment, warehousing, assignment, routing, batching, sequencing, and tardiness were considered.

Regarding the second research question, it was found that the most studied issue (54 articles) was related to routing, and in comparison, tardiness received the least attention with 6 articles. This indicates that researchers' tendency is to study the issue of routing compared to other aspects of picking operations (Figure 8). Through investigating the order-picking problems in the articles (based on Table 4), it was found that most of the studies were on routing with 26 works and batching and routing with 15 cases. This reflected the fact that the research base in the order-picking area is routing. One of the important points in the picking process improvement is the integrated review of all aspects of the picking process. For example, four studies simultaneously surveyed the categories of assignment, routing, and batching $[12,61,67,71]$, and one study simultaneously surveyed the categories of assignment, batching, routing, sequencing, and tardiness [20] (see Table 4). As can be observed in Table 7, most studies focused on batching and routing to increase productivity. However, Matusiak et al. [67] explored a concurrent survey on assignment, batching, and routing, and Chen et al. [22] simultaneously studied routing, batching, and sequencing to maximize productivity in OPS. Different combinations of picking problems were utilized to improve storage space (Table 8) and minimize the makespan (Table 9). In addition, according to the fields of study, the articles reviewed in this work can be approached in terms of either tactic or component. According to the research method of the present study, the selection of valid search engines can help to review the literature appropriate to the area of research. In the reviewed literature, three types of articles were observed: articles presenting new approaches and methods in the picking process, review articles, and articles focusing on the components of the order-picking process. The classification of these studies helps warehouse managers differentiate between planning problems, become aware of the minimum combinations used, and detect which planning problems should be simultaneously considered.

Considering the third research question of the present study, Figure 5 shows that one of the main uses of a cross-dock warehouse is to route the picker in cross aisles. Therefore, it is necessary to assign routes to reduce picker travel in a warehouse and decrease the number of visits to the block bypassing the aisle. In the previous studies, a classification of the warehouses can be seen. In Table 2 , it is obvious that parallel-aisle warehouses were the most studied warehouses.

\section{Conclusions}

New market developments such as e-commerce, globalization, rising customer expectations, and new market regulations have forced warehouses to handle more orders in less time. In this matter, awareness of the impact of individual planning on picking planning for performance management and thus increasing customer service are required 
in overall performance. In this paper, studies that highlighted the main issues of the picking process were classified through reviewing the literature. By focusing on planning problems that affect an economic goal, such as time-related performance or productivity indicators, problems were investigated as these goals are the most important warehouse operations. In this paper, regarding a combination of order-picking planning problems, articles reviewed by analyzing different tactical and operational planning problems simultaneously were classified with the aim of determining which planning problems are related, how various individual planning issues are related, and how can warehouse managers take advantage of the combination of multi-objective planning problems to cope with new market developments. The obtained results confirmed that all planning problems must be incorporated due to different time horizons of decisions made one after another. As different industry managers look for ideal, simple, intuitive, and reliable solutions, cost reduction solutions are suggested in the order-picking process. Table 3 indicates an insufficient balance between decision-making variables about planning problems as well as a tendency towards more studies about routing and storage space at a higher speed than other aspects. Additionally, taking the 27 articles on cost minimization, it is clear that this issue has not been sufficiently surveyed. It should be noted that cost reduction includes a wide range of issues, one of which is tardiness that can reduce costs. Although industrial automation has an increasing impact on the industry as well as the OPS system, the studies reviewed from 2014 onwards [6,18,21,30,36,41,42,50-61,64,66-69] continued to focus directly on warehouse activities such as routing, batching, and assignment to reduce costs. This shows the importance of costs in the OPS process, so that in this study, $77 \%$ of cost-related studies were published from 2014 onwards. Concerning the literature and methodologies of research works carried out in the area of order-picking, it was found that most of the research works emphasized mathematical programming methods with a $64 \%$ allocation percentage (Figure 10). Moreover, the genetic algorithm, ant colony, variable neighborhood search (VNS), particle swarm optimization (PSO), and other heuristic methods were significantly employed (Table 10).

Furthermore, based on Table 10, mathematical programming methods have been mainly used for routing and batching problems to explore the aspects of the picking process simultaneously. This suggests that the majority of researchers have tried to minimize distance in order to reduce cost and time, mainly because routing is metric and calculable. Moreover, at the operational level, there is still a need to integrate more planning problems and calculate the real-world features.

Despite the importance of human resources in the warehouse environment, a small number of articles have evaluated the labor planning problems, such as determining the daily labor force level, assigning the labor in order-picking areas, and assigning jobs to pickers $[6,7,65]$.

It should be further noted that as the warehouses offer multiple services to customers, the availability and performance of human resources ensure the quality of service to customers and the performance of order-picking. For instance, determining the level of the workforce combined with the assignment of order pickers and the planning problem makes focusing on the number of pickers a challenging opportunity for future research. Previous studies have mainly focused on reducing order-picking time. Working in an atmosphere with increasing pressure and limited time raises the likelihood of selection errors. In recent years, the number of articles analyzing multi-objective picking planning problems has risen dramatically. Nonetheless, currently, research works are mostly on the storage location, order batching, and routing. At a tactical level of picking problem, little attention has been paid to research. Previous studies have not only combined planning problems but have also simplified the order collection systems. The results developed in this paper indicate the need for more research on the congestion of warehouse aisles and the combination of picking operations problems in the future. In terms of cost reduction, the combination of tardiness with other planning problems has not yet been investigated. In addition, to improve efficiency, few studies have been performed in the field of assignment, sequencing, 
and tardiness, and the effect of different combinations of these problems on productivity improvement has not been studied. Moreover, the effect of combining planning problems has been only studied by Ardjmand et al. [12,46] and has received less attention. On the other hand, the effect of labor fatigue as well as workload balance on the combination of tardiness and other planning problems can be examined.

Author Contributions: Conceptualization, A.R.A.K. and D.J.; validation, M.K. and P.D.; formal analysis, D.J.; investigation, A.R.A.K. and D.J.; resources, A.R.A.K.; data curation, M.K.; writing-original draft preparation, A.R.A.K.; writing—review and editing, D.J.; visualization, P.D.; supervision, M.K. and D.J.; project administration, D.J. All authors have read and agreed to the published version of the manuscript.

Funding: This research received no external funding.

Institutional Review Board Statement: Not applicable.

Informed Consent Statement: Not applicable.

Data Availability Statement: Not applicable.

Conflicts of Interest: The authors declare no conflict of interest.

\section{References}

1. De Koster, R.; Le Duc, T.; Zaerpour, N. Determining the number of zones in a pick-and-sort order-picking system. Int. J. Prod. Res. 2012, 50, 757-771. [CrossRef]

2. Van Gils, T.; Ramaekers, K.; Caris, A.; de Koster, R.B. Designing efficient order-picking systems by combining planning problems: State-of-the-art classi- fication and review. Eur. J. Oper. Res. 2018, 267, 1-15. [CrossRef]

3. Franzke, T.; Grosse, E.H.; Glock, C.H.; Elbert, R. An investigation of the effects of storage assignment and picker routing on the occurrence of picker blocking in manual picker-to-parts warehouses. Int. J. Logist. Manag. 2017, 28, 841-863. [CrossRef]

4. Battini, D.; Calzavara, M.; Persona, A.; Sgarbossa, F. Additional effort estimation due to ergonomic conditions in order-picking systems. Int. J. Prod. Res. 2017, 55, 2764-2774. [CrossRef]

5. Žulj, I.; Kramer, S.; Schneider, M. A hybrid of adaptive large neighborhood search and tabu search for the order-batching problem. Eur. J. Oper. Res. 2018, 264, 653-664. [CrossRef]

6. Grosse, E.H.; Glock, C.; Jaber, M.Y.; Neumann, P. Incorporating human factors in order picking planning models: Framework and research opportunities. Int. J. Prod. Res. 2014, 53, 695-717. [CrossRef]

7. Grosse, E.H.; Glock, C.H.; Neumann, W.P. Human factors in order picking: A content analysis of the literature. Int. J. Prod. Res. 2016, 55, 1260-1276. [CrossRef]

8. Valle, C.A.; Beasley, J.E.; da Cunha, A.S. Optimally solving the joint order batching and picker routing problem. Eur. J. Oper. Res. 2017, 262, 817-834. [CrossRef]

9. Marchet, G.; Melacini, M.; Perotti, S. Investigating order-picking system adoption: A case-study-based approach. Int. J. Logist.-Res. Appl. 2015, 18, 82-98. [CrossRef]

10. Habazin, J.; Glasnović, A.; Bajor, I. Order Picking Process in Warehouse: Case Study of Dairy Industry in Croatia. Promet-Traffic Transp. 2017, 29, 57-65. [CrossRef]

11. Tompkins, J.A.; White, J.A.; Bozer, Y.A.; Tanchoco, J.M.A. Facilities Planning, 3rd ed.; John Wiley \& Sons: New York, NY, USA, 2010.

12. Ardjmand, E.; Shakeri, H.; Singh, M.; Bajgiran, O.S. Minimizing order picking makespan with multiple pickers in a wave picking warehouse. Int. J. Prod. Econ. 2018, 206, 169-183. [CrossRef]

13. Azadnia, A.H.; Taheri, S.; Ghadimi, P.; Mat Saman, M.Z.; Wong, K.Y. Order batching in warehouses by minimizing total tardiness: A hybrid approach of weighted association rule mining and genetic algorithms. Sci. World J. 2013, 2013, 246578. [CrossRef]

14. Henn, S. Order batching and sequencing for the minimization of the total tardiness in picker-to-part warehouses. Flex. Serv. Manuf. J. 2015, 27, 86-114. [CrossRef]

15. Park, J.; Kim, B.I. The school bus routing problem. Eur. J. Oper. Res. 2010, 202, 311-319. [CrossRef]

16. Kaur, A.; Kumar, A. A new method for solving fuzzy transportation problems using ranking function. Appl. Math. Model. 2011, 35, 5652-5661. [CrossRef]

17. Gupta, A.; Kumar, A. A new method for solving linear multi-objective transportation problems with fuzzy parameters. Appl. Math. Model. 2012, 36, 1421-1430. [CrossRef]

18. Kuo, R.; Kuo, P.; Chen, Y.R.; Zulvia, F.E. Application of metaheuristics-based clustering algorithm to item assignment in a synchronized zone order-picking system. Appl. Soft Comput. 2016, 46, 143-150. [CrossRef]

19. Scholz, A.; Henn, S.; Stuhlmann, M.; Wascher, G. A new mathematical programming formulation for the single-picker routing problem. Eur. J. Oper. Res. 2016, 253, 68-84. [CrossRef]

20. Scholz, A.; Schubert, D.; Wäscher, G. Order-picking with multiple pickers and due dates simultaneous solution of order batching, batch assignment and sequencing, and picker routing problems. Eur. J. Oper. Res. 2017, 263, 461-478. [CrossRef] 
21. Zhang, J.; Wang, X.; Chan, F.T.S.; Ruan, J. On-line order batching and sequencing problem with multiple pickers: A hybrid rule-based algorithm. Appl. Math. Model. 2017, 45, 271-284. [CrossRef]

22. Chen, T.L.; Cheng, C.Y.; Chen, Y.Y.; Chan, L.K. An efficient hybrid algorithm for integrated order batching, sequencing and routing problem. Int. J. Prod. Econ. 2015, 160, 158-167. [CrossRef]

23. Muter, I.; Öncan, T. Order batching and picker scheduling in warehouse order picking. IISE Trans. 2021. [CrossRef]

24. Cano, J.A.; Correa-Espinal, A.; Montoya, R.A.G. Mathematical programming modeling for joint order batching, sequencing and picker routing problems in manual order-picking systems. J. King Saud Univ.-Eng. Sci. 2020, 32, 219-228. [CrossRef]

25. Cano, J.A.; Cortés Achedad, P.; Campo, E.A.; Correa-Espinal, A. Solving the order batching and sequencing problem with multiple pickers: A grouped genetic algorithm. Int. J. Electr. Comput. Eng. IJECE 2021, 11, 2516-2524. [CrossRef]

26. Falagas, M.E.; Pitsouni, E.I.; Malietzis, G.A.; Pappas, G. Comparison of Pubmed, Scopus, web of science, and Google scholar: Strengths and weaknesses. Faseb. J. 2008, 22, 338-342. [CrossRef]

27. Wang, Q.; Waltman, L. Large-scale analysis of the accuracy of the journal classification systems of Web of Science and Scopus. J. Informetr. 2016, 10, 347e364. [CrossRef]

28. Gu, J.; Goetschalckx, M.; McGinnis, L.F. Research on warehouse design and performance evaluation: A comprehensive review. Eur. J. Oper. Res. 2010, 203, 539-549. [CrossRef]

29. Roodbergen, K.J.; Vis, I.; Don Taylor, G., Jr. Simultaneous determination of warehouse layout and control policies. Int. J. Prod. Res. 2015, 53, 3306-3326. [CrossRef]

30. Cheng, C.Y.; Chen, Y.Y.; Chen, T.L.; Yoo, J.W.J. Using a hybrid approach based on the particle swarm optimization and ant colony optimization to solve a joint order batching and picker routing problem. Int. J. Prod. Econ. 2015, 170, 805-814. [CrossRef]

31. Cortés, P.; Gómez-Montoya, R.A.; Muñuzuri, J.; Correa-Espinal, A. A tabu search approach to solving the picking routing problem for large-and medium-size distribution centres considering the availability of inventory and $\mathrm{K}$ heterogeneous material handling equipment. Appl. Soft Comput. 2017, 53, 61-73. [CrossRef]

32. De Vries, J.; De Koster, R.; Stam, D. Aligning order picking methods, incentive systems, and regulatory focus to increase performance. Prod. Oper. Manag. 2016, 25, 1363-1376. [CrossRef]

33. Henn, S.; Wäscher, G. Tabu search heuristics for the order batching problem in manual order-picking systems. Eur. J. Oper. Res. 2012, 222, 484-494. [CrossRef]

34. Hong, S.; Kim, Y. A route-selecting order batching model with the S-shape routes in a parallel-aisle order-picking system. Eur. J. Oper. Res. 2017, 257, 185-196. [CrossRef]

35. Isler, C.; Righetto, G.; Morabito, R. Optimizing the order-picking of a scholar and office supplies warehouse. Int. J. Adv. Manuf. Technol. 2016, 87, 2327-2336. [CrossRef]

36. Schrotenboer, A.H.; Wruck, S.; Roodbergen, K.J.; Veenstra, M.; Dijkstra, A.S. Order picker routing with product returns and interaction tardiness. Int. J. Prod. Res. 2017, 55, 6394-6406. [CrossRef]

37. Henn, S. Algorithms for on-line order batching in an order-picking warehouse. Comput. Oper. Res. 2012, 39, 2549-2563. [CrossRef]

38. Menéndez, B.; Bustillo, M.; Pardo, E.G.; Duarte, A. General variable neighborhood search for the order batching and sequencing problem. Eur. J. Oper. Res. 2017, 263, 82-93. [CrossRef]

39. Theys, C.; Bräysy, O.; Dullaert, W.; Raa, B. Using a TSP heuristic for routing order pickers in warehouses. Eur. J. Oper. Res. 2010, 200, 755-763. [CrossRef]

40. Berglund, P.; Batta, R. Optimal placement of warehouse cross-aisles in a picker-to-part warehouse with class-based storage. IIE Trans. 2011, 44, 107-120. [CrossRef]

41. Öztürkoğlu, Ö.; Hoser, D. A discrete cross aisle design model for order-picking warehouses. Eur. J. Oper. Res. 2019, 275, 411-430. [CrossRef]

42. Öztürkoğlu, Ö.; Gue, K.R.; Meller, R.D. A constructive aisle design model for unitload warehouses with multiple picking and deposit points. Eur. J. Oper. Res. 2014, 236, 382-394. [CrossRef]

43. Li, J.; Huang, R.; Dai, J.B. Joint optimization of order batching and picker routing in the online retailer's warehouse in China. Int. J. Prod. Res. 2017, 55, 447-461. [CrossRef]

44. Hsieh, L.F.; Huang, Y.C. New batch construction heuristics to optimise the performance of order-picking systems. Int. J. Prod. Econ. 2011, 131, 618-630. [CrossRef]

45. Matusiak, M.; de Koster, R.; Kroon, L.; Saarinen, J. A fast simulated annealing method for batching precedence-constrained customer orders in a warehouse. Eur. J. Oper. Res. 2014, 236, 968-977. [CrossRef]

46. Ardjmand, E.; Ghalehkhondabi, I.; Young, W.A., II; Sadeghi, A.; Weckman, G.R.; Shakeri, H. A hybrid artificial neural network, genetic algorithm and column generation heuristic for minimizing makespan in manual order picking operations. Expert Syst. Appl. 2020, 159, 113566. [CrossRef]

47. Valle, C.A.; Beasley, J.E. Order batching using an approximation for the distance travelled by pickers. Eur. J. Oper. Res. 2020, 284, 460-484. [CrossRef]

48. Clark, K.A.; Meller, R.D. Incorporating vertical travel into non-traditional cross aisles for unit-load warehouse designs. IIE Trans. 2013, 45, 1322-1331. [CrossRef]

49. Kübler, P.; Glock, C.H.; Bauernhansl, T. A new iterative method for solving the joint dynamic storage location assignment, order batching and picker routing problem in manual picker-to-parts warehouses. Comput. Ind. Eng. 2020, 147, 106645. [CrossRef] 
50. Chen, F.; Wang, H.; Xie, Y.; Qi, C. An ACO-based online routing method for multiple order pickers with congestion consideration in warehouse. J. Intell. Manuf. 2016, 27, 389-408. [CrossRef]

51. Mowrey, C.H.; Parikh, P.J. Mixed-width aisle configurations for order-picking in distribution centers. Eur. J. Oper. Res. 2014, 232, 87-97. [CrossRef]

52. Pan, J.C.H.; Shih, P.H.; Wu, M.H. Order batching in a pick-and-pass warehousing system with group genetic algorithm. Omega 2015, 57, 238-248. [CrossRef]

53. Kulak, O.; Sahin, Y.; Taner, M.E. Joint order batching and picker routing in single and multiple-cross-aisle warehouses using cluster-based tabu search al-gorithms. Flex. Serv. Manuf. J. 2012, 24, 52-80. [CrossRef]

54. Henn, S.; Koch, S.; Gerking, H.; Wäscher, G. A U-shaped layout for manual order-picking systems. Logist. Res. 2016, 6, 245-261. [CrossRef]

55. Acimovic, J.; Graves, S.C. Making better fulfillment decisions on the fly in an online retail environment. Manuf. Serv. Oper. Manag. 2014, 17, 34-51. [CrossRef]

56. Akilbasha, P.; Atarajan, P.G. An innovative exact method for solving fully interval integer transportation problems. Inform. Med. Unlocked 2018, 11, 95-99. [CrossRef]

57. Battini, D.; Glock, C.H.; Grosse, E.H.; Persona, A.; Sgarbossa, F. Human energy expenditure in order-picking storage assignment: A bi-objective method. Comput. Ind. Eng. 2016, 94, 147-157. [CrossRef]

58. Bevan, S. Economic impact of musculoskeletal disorders (MSDs) on work in Europe. Best Pract. Res. Clin. Rheumatol. 2015, 29, 356-373. [CrossRef]

59. Cergibozan, Ç.; Tasan, A.S. Order batching operations: An overview of classification, solution techniques, and future research. J. Intell. Manuf. 2019, 30, 335-349. [CrossRef]

60. Çeven, E.; Gue, K.R. Optimal wave release times for order fulfillment systems with deadlines. Transp. Sci. 2015, 51, 52-66. [CrossRef]

61. Chabot, T.; Lahyani, R.; Coelho, L.C.; Renaud, J. Order-picking problems underweight, fragility and category constraints. Int. J. Prod. Res. 2017, 55, 6361-6379. [CrossRef]

62. Chackelson, C.; Errasti, A.; Ciprés, D.; Lahoz, F. Evaluating order-picking performance trade-offs by configuring main operating strategies in a retail dis- tributor: A design of experiments approach. Int. J. Prod. Res. 2013, 51, 6097-6109. [CrossRef]

63. Chien, C.M.; Gong, Y.; De Koster, R.; VanNunen, J. A flexible evaluative framework for order-picking systems. Prod. Oper. Manag. 2010, 19, 70-82. [CrossRef]

64. Ene, S.; Öztürk, N. Storage location assignment and order-picking opti- mization in the automotive industry. Int. J. Adv. Manuf. Technol. 2012, 60, 787-797. [CrossRef]

65. Grosse, E.H.; Glock, C.H.; Jaber, M.Y. The effect of worker learning and forgetting on storage reassignment decisions in orderpicking systems. Comput. Ind. Eng. 2013, 66, 653-662. [CrossRef]

66. Manzini, R.; Accorsi, R.; Gamberi, M.; Penazzi, S. Modeling class-based storage assignment over life cycle picking patterns. Int. J. Prod. Econ. 2015, 170, 790-800. [CrossRef]

67. Matusiak, M.; De Koster, R.; Saarinen, J. Utilizing individual picker skills to improve order batching in a warehouse. Eur. J. Oper. Res. 2017, 263, 888-899. [CrossRef]

68. Schwerdfeger, S.; Boysen, N. Order-picking along a crane-supplied pick face: The SKU switching problem. Eur. J. Oper. Res. 2017, 260, 534-545. [CrossRef]

69. Tappia, E.; Roy, D.; De Koster, R.; Melacini, M. Modeling, analysis, and design insights for shuttle-based compact storage systems. Transp. Sci. 2017, 51, 269-295. [CrossRef]

70. Van Gils, T.; Ramaekers, K.; Braekers, K.; Depaire, B.; Caris, A. Increasing order-picking efficiency by integrating storage, batching, zone picking, and routing policy decisions. Int. J. Prod. Econ. 2018, 197, 243-261. [CrossRef]

71. Chun, C.-C.; Kang, J.-R.; Hou, C.-C.; Cheng, C.Y. Joint order batching and picker Manhattan routing problem. Comput. Ind. Eng. 2016, 95, 164-174.

72. Calzavara, M.; Glock, C.H.; Grosse, E.H.; Persona, A.; Sgarbossa, F. Analysis of economic and ergonomic performance measures of different rack layouts in an order-picking warehouse. Comput. Ind. Eng. 2017, 111, 527-536. [CrossRef]

73. Davarzani, H.; Norrman, A.J. Toward a relevant agenda for warehousing research: Literature review and practitioners' input. Logist. Res. 2015, 8, 1-18. [CrossRef]

74. Glock, C.H.; Grosse, E.H. Storage policies and order-picking strategies in u shaped order-picking systems with a movable base. Int. J. Prod. Res. 2012, 50, 4344-4357. [CrossRef]

75. Gong, Y.; De Koster, R. A review on stochastic models and analysis of warehouse operations. Logist. Res. 2011, 3, 191-205. [CrossRef]

76. Thomas, L.M.; Meller, R.D. Analytical models for warehouse configuration. IIE Trans. 2014, 46, 928-947. [CrossRef]

77. Vanheusden, S.; Van Gils, T.; Braekers, K.; Ramaekers, K.; Caris, A. Analysing the effectiveness of workload balancing measures in order-picking operations. Int. J. Prod. Res. 2021, 1-25. [CrossRef]

78. Glock, C.H.; Grosse, E.H.; Elbert, R.M.; Franzke, T. Maverick picking: The impact of modifications in work schedules on manual order-picking processes. Int. J. Prod. Res. 2017, 55, 6344-6360. [CrossRef]

79. Lerher, T. Travel time model for double-deep shuttle-based storage and re-trieval systems. Int. J. Prod. Res. 2015, 54, 2519-2540. [CrossRef] 
80. Neumann, W.P.; Medbo, L. Ergonomic and technical aspects in the redesign of material supply systems: Big cases vs. narrow cases. Int. J. Ind. Ergon. 2010, 40, 541-548. [CrossRef]

81. Yu, Y.; De Koster, R.; Guo, X. Class-based storage with a finite number of items: Using more classes is not always better. Prod. Oper. Manag. 2015, 24, 1235-1247. [CrossRef]

82. Lee, H.-Y.; Murray, C.C. Robotics in order picking: Evaluating warehouse layouts for pick, place, and transport vehicle routing systems. Int. J. Prod. Res. 2018, 57, 5821-5841. [CrossRef]

83. Ho, Y.C.; Lin, J.W. Improving order-picking performance by converting a sequential zone-picking line into a zone-picking network. Comput. Ind. Eng. 2017, 113, 241-255. [CrossRef]

84. Andriansyah, R.; De Koning, W.W.H.; Jordan, R.M.E.; Etman, L.F.P.; Rooda, J.E. A process algebra based simulation model of a miniload-workstation order picking system. Comput. Ind. 2011, 62, 292-300. [CrossRef]

85. Koch, S.; Wäscher, G. A grouping genetic algorithm for the order batching problem in distribution warehouses. J. Bus. Econ 2016, 86, 131-153. [CrossRef]

86. Schleyer, M.; Gue, K. Throughput time distribution analysis for a one-block warehouse. Transp. Res. Part E: Logist. Transp. Rev. 2012, 48, 652-666. [CrossRef]

87. Tang, L.; Wang, G.; Liu, J.; Liu, J. A combination of Lagrangian relaxation and column generation for order batching in steelmaking and continuous-casting production. Nav. Res. Logistics. (NRL) 2011, 584, 370-388. [CrossRef]

88. Elbert, R.M.; Franzke, T.; Glock, C.H.; Grosse, E.H. The effects of human behavior on the efficiency of routing policies in order picking: The case of route deviations. Comput. Ind. Engineering. Ind. Eng. 2017, 111, 537-551. [CrossRef]

89. Letchford, A.N.; Nasiri, S.D.; Theis, D.O. Compact formulations of the Steiner traveling salesman problem and related problems. Eur. J. Oper. Res. 2013, 228, 83-92. [CrossRef]

90. Leung, K.; Choy, K.; Siu, P.K.; Ho, G.; Lam, H.; Lee, C.K. A B2C e-commerce intelligent system for re-engineering the e-order fulfilment process. Expert Syst. Appl. 2018, 91, 386-401. [CrossRef]

91. Lu, W.; McFarlane, D.; Giannikas, V.; Zhang, Q. An algorithm for dynamic order-picking in warehouse operations. Eur. J. Oper. Res. 2016, 248, 107-122. [CrossRef]

92. Pan, J.C.H.; Wu, M.H. Throughput analysis for order-picking system with multiple pickers and aisle congestion considerations. Comput. Oper. Res. 2012, 39, 1661-1672. [CrossRef]

93. Feng, X.; Hu, X. A Heuristic Solution Approach to Order Batching and Sequencing for Manual Picking and Packing Lines considering Fatiguing Effect. Sci. Program. 2021, 2021, 8863391. [CrossRef]

94. Scholz, A.; Wäscher, G. Order batching and picker routing in manual orderpicking systems: The benefits of integrated routing. Cent. Eur. J. Oper. Res. 2017, 25, 491-520. [CrossRef]

95. Hong, S.; Johnson, A.L.; Peters, B.A. Order batching in a bucket brigade order-picking system considering picker blocking. Flex. Serv. Manuf. J. 2016, 28, 425-441. [CrossRef]

96. Giannikas, V.; Lu, W.; Robertson, B.; McFarlane, D. An interventionist strategy for warehouse order picking: Evidence from two case studies. Int. J. Prod. Econ. 2017, 189, 63-76. [CrossRef] 